\title{
Fundamental Analysis of the Usability of an Angle-Resolved Scattered Light Sensor for Monitoring Vibratory Finishing Processes Based on Ray Tracing Simulations
}

\author{
François Torner,a, Jayanti Das ${ }^{2, b}$, Gerhard Stelzer ${ }^{1, a}$, \\ Barbara Linke ${ }^{2, b}$ and Jörg Seewig ${ }^{1, a}$ \\ ${ }^{1}$ Gottlieb-Daimler-Str., Building 44, 67663 Kaiserslautern, Germany \\ 21 Shields Ave, Davis, CA 95616, USA \\ atorner@mv.uni-kl.de, bjydas@ucdavis.edu
}

\begin{abstract}
Keywords: ray tracing, virtual optical measurement, optical sensors, angle-resolved scattered light sensor, vibratory finishing.
\end{abstract}

\begin{abstract}
The angle-resolved scattered light sensor OS500 is an optical measuring device that is becoming more and more frequently used in industrial applications and for the characterization of surfaces in general as well as for measuring roughness and shape. The angle-resolved measurement principle allows the statistical distribution of the gradients of a surface, resulting from the reflectance of the light at the flank angles of the areas examined, to be measured and consequently enables the geometric surface texture to be evaluated. Thus the topography of surfaces is not measured; instead the gradients are evaluated. Since the scattered light sensor measures angles and not distances, the sensor is immune to out-of-plane vibrations in the direction of measurement. Another distinct characteristic of the scattered light sensor is the high degree of sensor dynamics, which when combined with the statistical analysis of the surface angles, allows even the finest changes in the surface structure to be detected. Accordingly, it makes sense to use the sensor to monitor processes in which the surfaces and their structures change only slightly during the manufacturing process. One such process is so-called vibratory finishing. This process and several other manufacturing processes geared towards sustainable manufacturing methods are being examined by the "Department of Mechanical and Aerospace Engineering" at the University of California, Davis (CA, USA). On the basis of a ray tracing model, simulations calculations, meaning only virtual measurements, will demonstrate the suitability of the sensor for monitoring manufacturing.
\end{abstract}

\section{Introduction}

Angle-resolved scattered light measurement technology can be used for the characterization of geometric surfaces as well as for measurement of roughness and shape. As described in [1, 2], shapes can be measured by integrating surface gradients. Technology that measures shape and roughness is useful in the manufacturing of wafers for producing computer chips as well for general applications involving industrial quality control of micro-finished surfaces. This topic is examined in [3], which also looks at the aesthetic aspects. Use of the underlying measurement principle is widespread. And a modified version is used for other applications, e.g. to analyze surface tribology [4] or "specular gloss" [5] as well as to detect faults and defects in surfaces. The angle-resolved measurement principle allows the statistical distribution of the gradients of a surface to be measured and the geometric surface texture to be characterized by examining the statistical distribution of scattering angles resulting from the diffuse reflectance at the flank angles. Because it is a physical measurement principle, scattered light measurement technology does not measure topography data; it only evaluates gradients. The OS500 sensor examined here, made by Optosurf $\mathrm{GmbH}$, evaluates only homogeneously illuminated round measuring spots. The diameter of the measuring spot is $D=0.9 \mathrm{~mm}$ in the ray tracing model applied here. The underlying physical principle is based on the so-called mirror facet model (Refer to page 2, bottom). Since the scattered light sensor measures 
angles and not distances, the sensor is immune to vibrations in the direction of measurement - socalled out-of-plane vibrations. The results could be e.g. the evaluation of the $M$ value and the $A_{q}$ value (Refer to [6]), which describe the mean gradient of a surface and the standard deviation of the surface angle in the direction of measurement. These values have no direct correlation to the common roughness parameters $R_{a}$ and $R_{z}$ [7] or to the $3 D$ parameters $S_{a}$ and $S_{z}$ defined in [8] . The common roughness parameters are often used in industrial tactile and optical applications to characterize geometric surfaces, but the values themselves have only limited significance. This situation has already been explained in detail in [9]. The essential advantage of angle-resolved scattered light sensors is that, because of the strong dynamics of the photo-sensitive diodes and the statistical analysis, even the slightest changes in the surface structure can be measured. So the sensor is ideal for e.g. monitoring processes in which very fine changes in a surface structure have to be characterized. One such process is vibratory finishing, which will be dealt with in detail here. Ray tracing methods are relied on to calculate the geometric ray propagation and determine whether the sensor is suitable for the respective application. Since the scattered light sensor is based on the mirror facet model mentioned previously, ray tracing works particularly well for the analysis performed here. Tessellated data can be applied to mathematically describe components such as lenses as well as geometric surfaces in the form of such facets.

\section{Fundamental Information on Angle-resolved Scattered Light Sensor}

How the angle-resolved scattered light sensor works is explained as follows. An objective with a constant focal length is used to focus the collimated light from an LED onto a geometric surface. A light spot with homogeneous intensity distribution forms on the surface. The surface texture causes the focused light to scatter beyond the measuring spot. The mirror facet theory states that every incidental ray can be assigned a distinct reflection angle that is twice the local surface angle. The mirror facets are differentiated by single, discrete and equidistant measuring points. The reflected light is then displayed on a diode array with the aid of the objective (Refer to Fig. 1, left illustration). The angle-resolved scattered light sensor OS500 utilizes 32 photodiodes, arranged in an array, that measure scattering angle distribution with dynamics of 16 bits in one dimension. The roughness of a surface in the direction of measurement can then be characterized applying the resulting distribution. And with the center of gravity of the distribution, the mean gradient of the surface can be calculated. When the surface structure is isotropic, sensor alignment and thus diode array alignment are irrelevant. In this case the sensor cuts the resulting scattering cone and evaluates it according to the alignment of the diode array. When the surface is anisotropic, e.g. a ground surface, the directional dependency (anisotropy) of the surface structure must be taken into consideration when aligning the sensor.

\section{Virtual Measurement of Geometric Surfaces on the Basis of Scattered Light}

Virtual measurements were performed to determine whether the scattered light sensor is suitable for evaluation of vibratory-finished surfaces. A complete model of the sensor was created and can be used as a ray tracing model for virtual measurement of synthetically generated surfaces as well as of surfaces that have actually been measured. The basic principles of this virtual, optical measurement process are explained here.

The virtual measurements are based on non-sequential ray tracing methods that allow the geometric beam diffusion to be calculated by specifying the optical components of the sensor and the known topography. This is how this method differs from the principle of describing the optimal, mathematical transmission characteristics as explained in [2]. In this case, a grid based on the standard tessellation language (STL) represents the topography of a surface. The fundamental principle for generating the triangles to describe the geometric surface, so-called mirror facets, has already been explained in [10]. Applying the methods described here allows mirror facets to be 
generated and thus the reflection behavior of surfaces - and on that basis the scattered light distribution - to be realistically approximated.

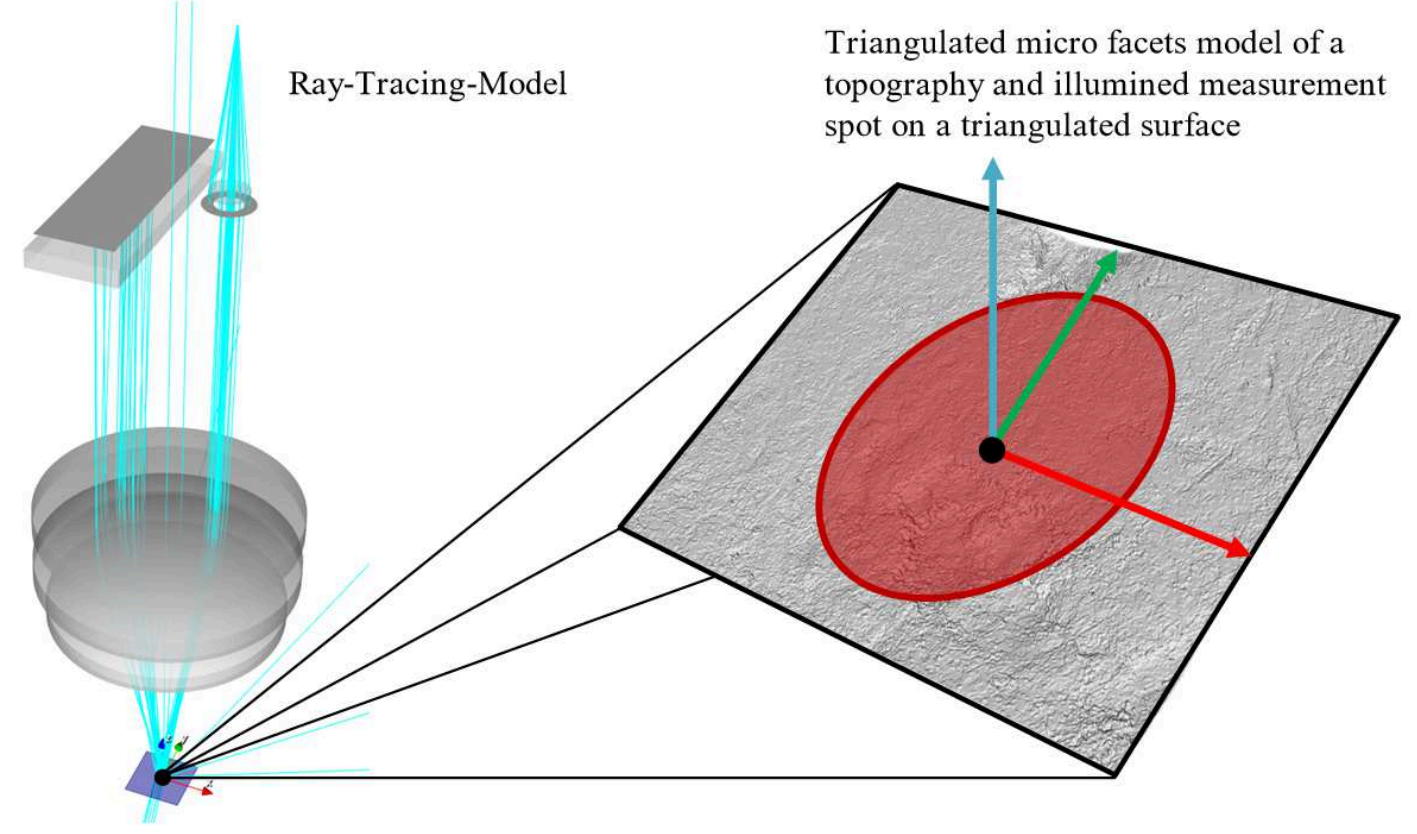

Figure 1. Non-sequential ray tracing model of the angle-resolved scattered light sensor and detailed view of a topography (1024 x 1280 measuring points) measured and triangulated with a confocal microscope, in the form of a mirror facet model as specified by [1]. Illustrations created with the Visualization Tool Kit (VTK).

The resulting scattering angle distribution is a factor of the intensity assigned to each individual light ray and the intensity as a consequence of the radiation properties of the virtual light source as well as the arrangement of the geometric components in space. The arrangement and properties of the optical components are available from the manufacturer of the scattered light sensor. Evaluations performed in conjunction with the transfer characteristics of the sensor confirm that the arrangement and properties are correct. Fig. 1 shows how the non-sequential VTK-based ray tracing model was set up. The intensity distribution can be measured on a virtual, planar detector within the virtual space. The VTK program also has a post-processing feature that offers the option of measuring the intensity distributions and analyzing the virtual data after the ray tracing process. When mathematical aspects are applied, the local intensity values that can be measured with the virtual detector correspond to geometric intersections of light rays that spread out linearly in restricted spaces. The wave character of the light is neglected when these modeling approaches are used. Because the resolution of the virtual detector is laterally limited, multiple ray interactions with the same pixel of a virtual detector lead to a higher, locally measurable intensity value, which has to be corrected as a factor of the number of intersections. The calculated intensity values can then be used to calculate parameters and characterize the geometric surface. 

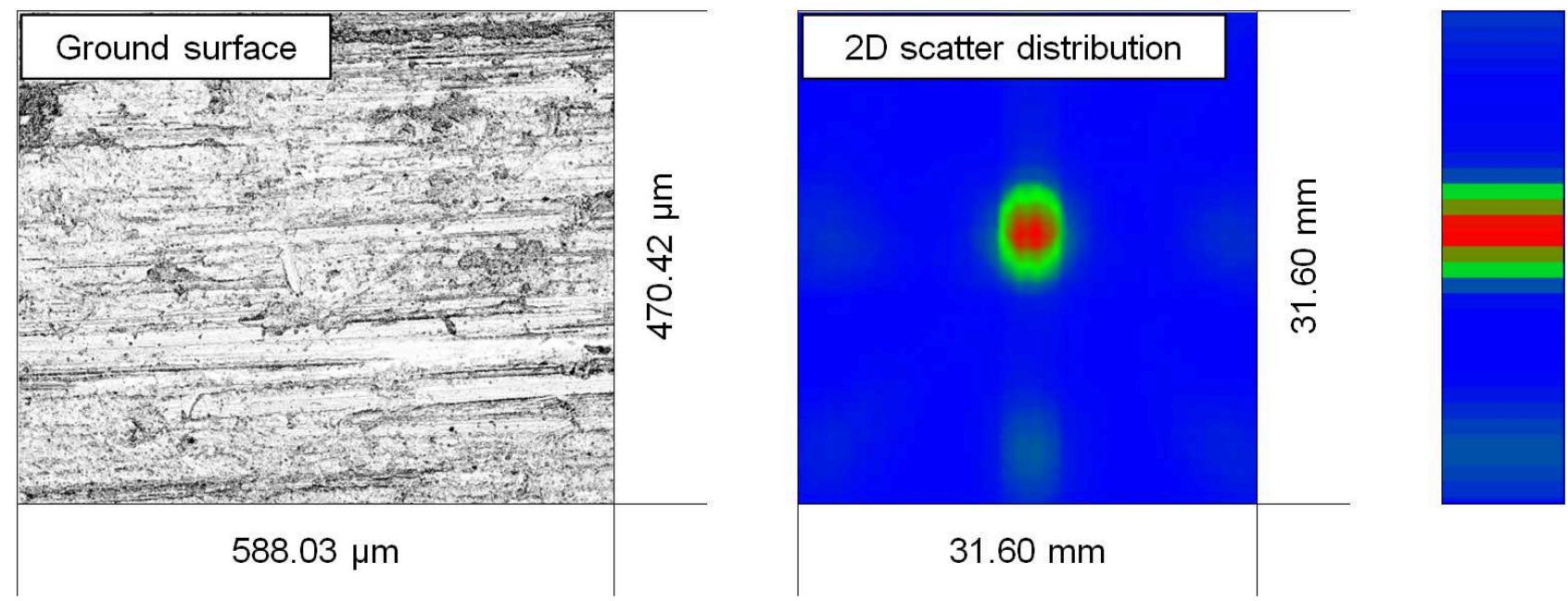

Figure 2. Left: Gray-scale image of a triangulated, ground surface (image created with VTK); center: scattering cone; right: color-coded, two-dimensional scattering angle distribution, measured with a virtual planar-detector while assuming perfect reflection behavior and illustration of the calculated, one-dimensional scattering angle distribution.

Triangulated topography data, measured with a Zeiss confocal microscope, type Axio CSM 700, at the AMCaT lab at the College of Engineering, University of California, Davis was utilized to characterize surfaces. The process used a objective with $20 \mathrm{x}$ magnification as well as a numerical aperture $\mathrm{NA}=0.6$. This objective was selected because of the relatively high acceptance angle, allowing greater surface gradients to be measured. The consequential, smaller measuring areas were acceptable. Fig. 2 shows a vertical view, measured with an objective and 20x magnification of such a triangulated topography rendered with VTK. Because of the limited size of the measuring area and the lack of stitching options to expand the measuring area, the topography was scaled (factor of 2). This increased the size of the measuring area and enabled the measuring spot of the virtual sensor model with a diameter of $D=0.9 \mathrm{~mm}$ to be projected in whole onto the virtual surface. The surface gradients and their characteristics were not modified when scaled.

In the course of testing, different types of geometric surfaces, each calculated using confocal data, were measured with the sensor model OS500. Examples of the fundamental, color-coded characteristic topographies of the surfaces and the corresponding material ratio curves are shown in Fig. 3. Four different types of manufacturing processes, i.e. extrusion, grinding, sawing, and tumbling were used in this study. 304 stainless steel were used as test materials having dimension of 1 inch $\times 1$ inch $\times 1$ inch square cubes. A Dremel 4000 handheld power tool and resin bonded alumina sanding bands were used to prepare ground surfaces under $5000 \mathrm{rpm}$ rotational cutting speed. All grinding operations were running under dry cutting conditions, performed by the same subject to improve the consistency of machining process. Whereas, extruded surfaces are prepared by fixed cross-sectional die either by heat treated or cold worked condition. Sawed surfaces were prepared by using narrow spaced teeth named saw blade. The surfaces can be characterized with the aid of function-oriented values. The differences between the various surfaces are obvious when one examines the material ratio curves. While the rolled surface shows a relatively wide plateau around the core roughness, the core roughness is unevenly distributed on the sawed surface. Thus higher values are to be expected for the $3 \mathrm{D}$ parameter $\mathrm{S}_{\mathrm{k}}$ (Refer to [8]). 

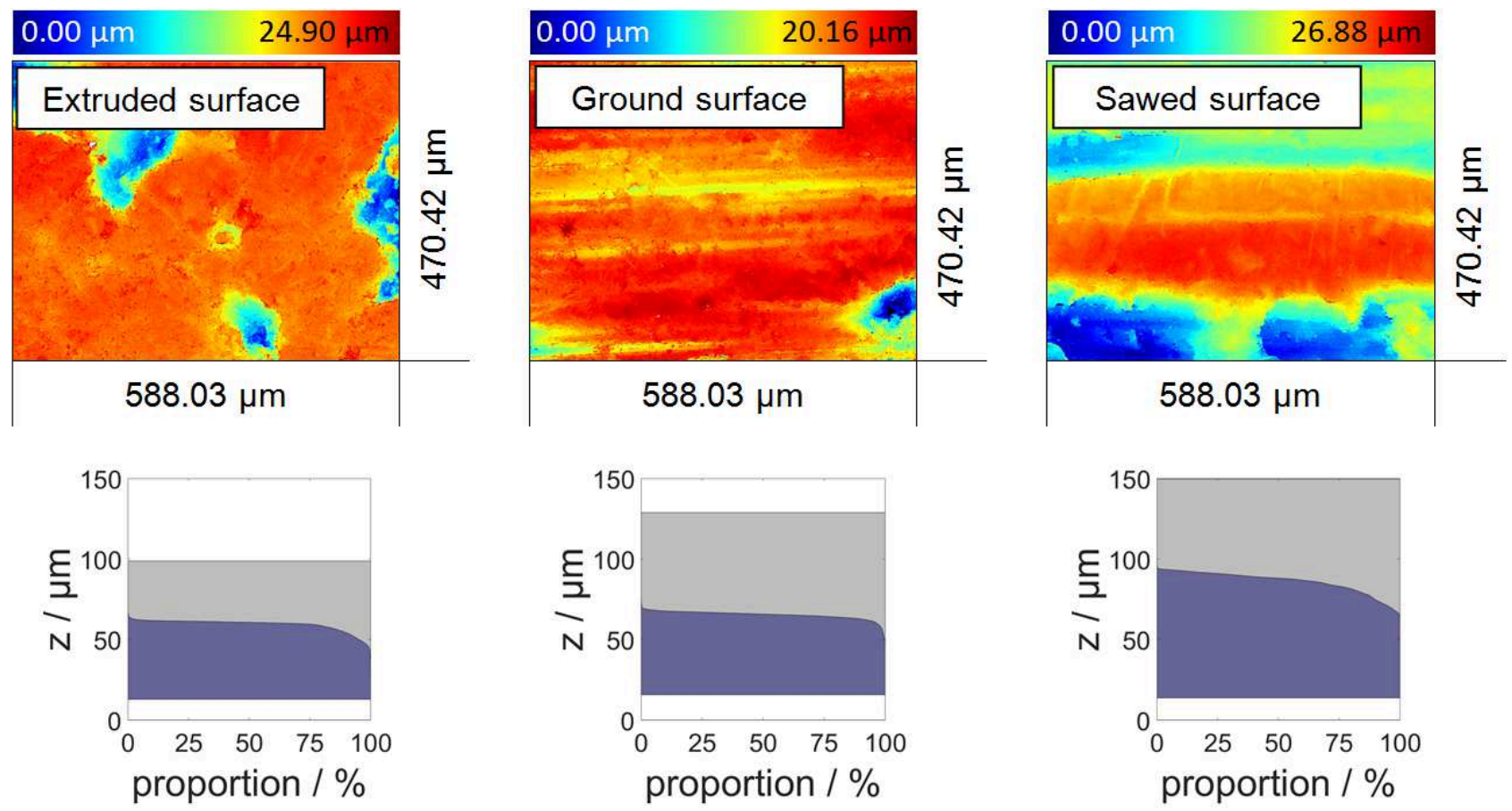

Figure 2. Top row: Color-coded topographies, measured with a Zeiss confocal microscope. Bottom row: Material ratio curves of the characteristic surfaces shown above (left: extruded surface; center: ground surface; right: sawed surface).

The distribution of the gradient is an essential aspect of surface measurement. The maximum surface angle $\theta_{C, \max }$ that can be measured with a confocal microscope is calculated as a factor of the numerical aperture NA of the objective and of the refractive index of the environment $n_{\text {air }} \cong 1.00$. Thus the angle is

$$
\theta_{C, \max }=\frac{1}{2} \cdot \varphi_{C, \mathrm{NA}}=\frac{1}{2} \cdot \arcsin \left(\frac{\mathrm{NA}}{n_{\text {air }}}\right) \cong 18.43^{\circ} \text {. }
$$

The greatest surface angle that can be measured with an angle-resolved scattered light sensor is a factor of the objective aperture and its focal length. The modeled sensor OS500 covers a maximum angle range of $2 \cdot \varphi_{\mathrm{SLS}, \mathrm{NA}}=32^{\circ}$. Thus the following applies to the maximum surface angle that can be measured:

$$
\theta_{\mathrm{SLS}, \max }=\frac{1}{2} \cdot \varphi_{\mathrm{SLS}, \mathrm{NA}}=8^{\circ} \ll \theta_{C, \max } .
$$

Consequently, the confocally measured surfaces do not pose a limit in regard to the measuring range of the angle-resolved scattered light sensor.

\section{Approaches for Monitoring Vibratory Finishing Processes}

Characterization of vibratory finishing processes is a potential application for the angle-resolved scattered light sensor OS500, which will be examined here. The vibratory finishing process uses any number of grinding tools that apply friction to create abrasion and stochastically process the surface of metal objects. Vibratory finishing is often used in technical applications for final processing to achieve certain surface properties. Increasing the material contact area should be mentioned in this context, because it is relevant e.g. when finishing gear wheels. Different parameters can be used to characterize machined surfaces. The parameters specified in [8] are particularly suitable, because there is a correlation to the material distribution of a topography. This 
allows the core roughness $\mathrm{S}_{\mathrm{k}}$ to be calculated as an Abbott curve with the aid of the areal material ratio. Fig. 4 illustrates the method used to determine function-oriented values. The areal material ratio can be increased with vibratory finishing. This is achieved particularly by reducing the peaks, represented by the $3 \mathrm{D}$ parameter $\mathrm{S}_{\mathrm{pk}}$ describing the reduced height of the peaks. Other parameters such as $\mathrm{S}_{\mathrm{mr} 1}$ and $\mathrm{S}_{\mathrm{mr} 2}$, which can be derived from the Abbott curve, can be expected to be impacted as well. While the processing of some surfaces such as aluminum is relatively simple to monitor, monitoring the finishing process for steel costs a lot of time. This is attributable to the greater hardness and the longer time required for the abrasive stripping process. Monitoring is especially difficult because a lot of time is needed for topography measurements, e.g. with a confocal microscope or a short-coherent interferometer. In contrast, the scattered light sensor works with measuring frequencies up to $2 \mathrm{kHz}$ and provides statistical information in gradient distribution of the geometric surface. So using the sensor between the individual processing steps offers significantly more information in much shorter measuring times.
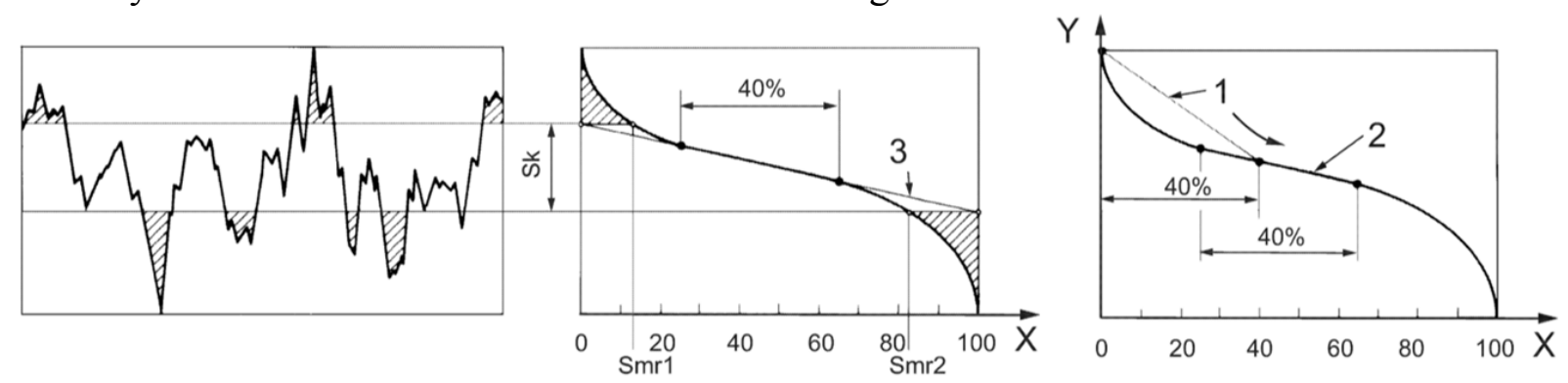

Figure 3. Determination of function-oriented parameters as a factor of the areal material ratio as specified by [8]. Illustration of the core roughness $S_{k}$ of a surface as well as the material ratios of the peak heights and valley heights $\mathrm{S}_{\mathrm{mr} 1}$ and $\mathrm{S}_{\mathrm{mr} 2}$ as specified by [8].

The problem with angle-resolved scattered light measurement technology is that the functionoriented parameters derived from the material ratio curve (See Fig. 4) cannot be directly portrayed with the scattered light sensor. But since grinding strongly impacts these parameters, a correlation analysis between these parameters and a parameter that can be measured with the scattered light sensor has to be performed. As stated in [8], one parameter that can be shown with the sensor is the mean square gradient of the scale-limited surface. Depending on the topography $z(x, y)$ as well as the vertically projected infinitesimal surface element $d A=d x \cdot d y$ of the topography, the parameter is calculated to be

$$
\mathrm{S}_{\mathrm{dq}}=\sqrt{\frac{1}{A} \cdot \int_{\partial y} \int_{\partial x}\left(\left(\frac{\partial z(x, y)}{\partial x}\right)^{2}+\left(\frac{\partial z(x, y)}{\partial y}\right)^{2}\right) \cdot d x \cdot d y} .
$$

The parameter $\mathrm{S}_{\mathrm{dq}}$ is the two-dimensional equivalent of the variance of the scattering angle distribution and is stated and calculated with the aid of the $\mathrm{A}_{\mathrm{q}}$ value specified in section 4.4 .2 of [6]. It is calculated directly from the scattering angle distribution $H\left(\varphi_{n}\right)$ as a factor of the discreet scattering angle $\varphi_{n}$. If the topography is anisotropic, the following applies to the surface angle $\theta_{x}$ in $x$ direction

$$
\theta_{x}=\frac{1}{2} \cdot \varphi=\arctan \left(\frac{\partial z(x, y)}{\partial x}\right)
$$

$\varphi$ is the measured reflection angle in this case and is equivalent to twice the surface angle. The following applies under these conditions 


$$
\hat{\mathrm{S}}_{\mathrm{dq}}(\varphi)=\sqrt{\frac{1}{A} \cdot \int_{\partial A} \tan ^{2}\left(\frac{1}{2} \cdot \varphi\right) \cdot d x \cdot d y}
$$

with

$$
\tan \left(\frac{1}{2} \cdot \varphi\right) \cong \frac{1}{2} \cdot \varphi \Rightarrow \hat{\mathrm{S}}_{\mathrm{dq}}^{2}(\varphi) \cong \frac{1}{4} \cdot \int_{\partial A} \varphi^{2}(x, y) \cdot \frac{d x \cdot d y}{A} .
$$

For smaller gradients, the square of $\hat{\mathrm{S}}_{\mathrm{dq}}(\varphi)$ is approximately proportional to the parameter determined with the scattered light sensor

$$
\mathrm{A}_{\mathrm{q}}=k_{A q} \cdot \sum_{n=1}^{N}\left(\varphi_{n}-\mathrm{M}\right)^{2} \cdot H\left(\varphi_{n}\right)
$$

The correction factor $k_{A q}$ normalizes this value. If it is assumed that a surface $A$ to be measured is homogeneously illuminated, the scattering angle distribution can then be directly translated to the described integral pursuant to equation 3.

\section{Impact of Material Stripping in Function-oriented Parameters}

Examination of the material ratio curve (Abbott curve) allows parameters of geometric surfaces that change during vibratory finishing to be calculated. It is to be expected that the mechanical force applied during vibratory finishing will remove particularly the peaks from the topography. This abrasive process can be detected in Fig. 5 when one looks at confocally measured, color-coded topographies at different processing times. Especially a change in $S_{p k}$ is to be expected in this context. The other parameters are impacted by the grinding process as well.
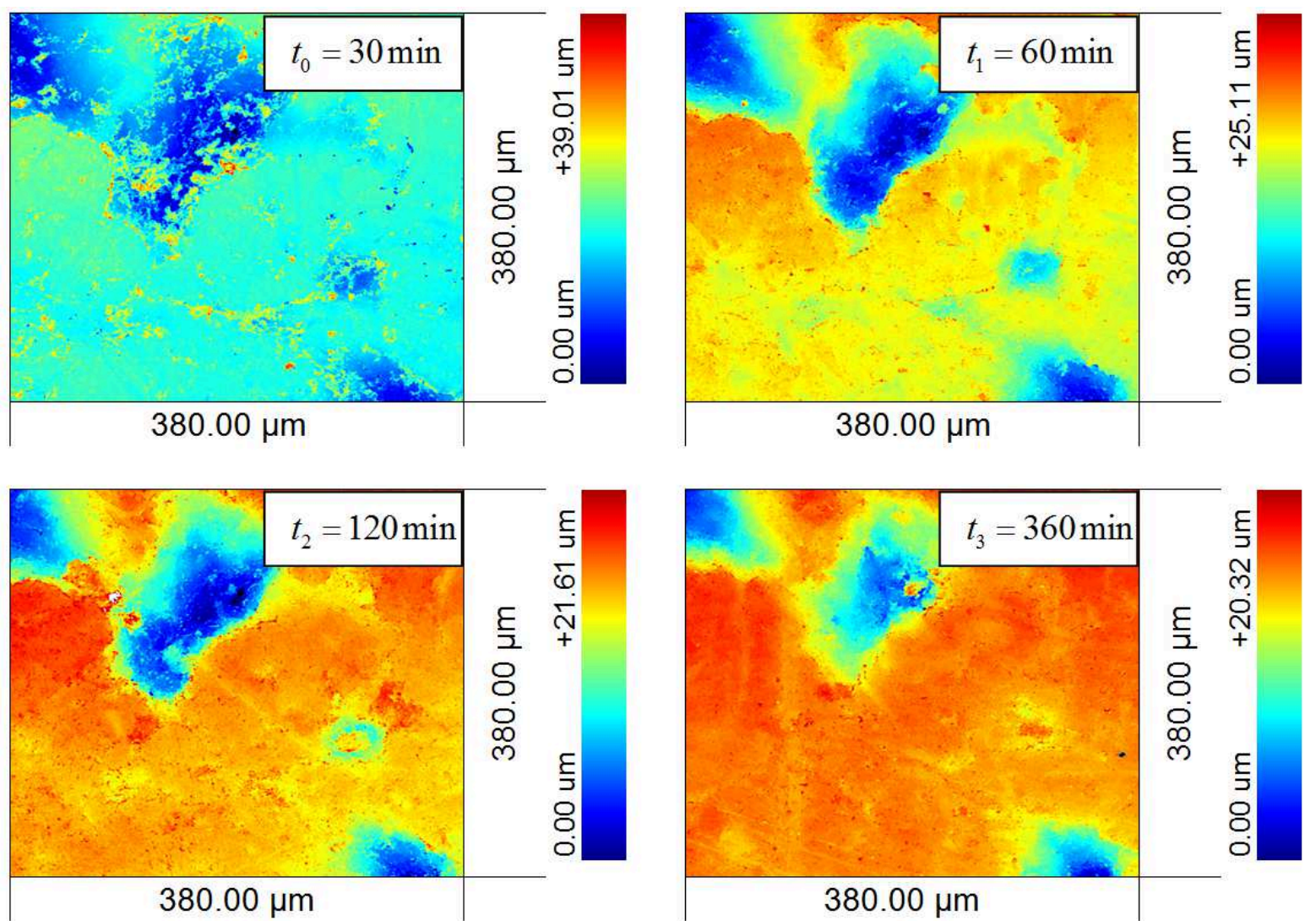

Figure 4. Changes in topography caused by the vibratory finishing process (rolled surface, sample 1). Depiction of color-coded topography at the discrete time steps $t_{0}$ to $t_{3}$. 
First the Abbott curve for an unprocessed surface is examined. The curve is defined by the function $f(x)$ in the range of $x \in[\Delta x ; 1]$, and $\Delta x=0$. The variable $x$ describes the material ratio. If it is assumed that the finishing process removes material only from the peaks of the topography, stripping can be described in simplified terms by shifting the Abbott curve by $\Delta x \geq 0$. The secant $h_{\Delta x}(x)$ can be calculated following the information in [8], chapter 5.2 with

$$
h_{\Delta x}(x)=\frac{f\left(x_{s}\right)-f(\Delta x)}{x_{s}-\Delta x} \cdot(x-\Delta x)+f(\Delta x) \stackrel{\Delta x=0}{=} \frac{f\left(x_{s}\right)-f(0)}{x_{s}} \cdot x+f(0)
$$

(Refer to Fig. 6). The tangent point $x_{s}$ is then calculated as

$$
x_{s}: \frac{\partial}{\partial x_{s}}\left(\frac{\partial h_{\Delta x}(x)}{\partial x}\right)=0 \Rightarrow \frac{\partial}{\partial x_{s}}\left(\frac{f\left(x_{s}\right)-f(\Delta x)}{x_{s}-\Delta x}\right)=0 \Rightarrow f^{\prime}\left(x_{s}\right)=-\frac{f\left(x_{s}\right)-f(\Delta x)}{x_{s}-\Delta x}
$$

Chapter 5.2 of [8] specifies that the equivalent line is calculated between the limits $x_{s}$ and $x_{t}(\Delta x)=x_{s}-0,4 \cdot(1-\Delta x)$ applying linear regression. The linear equation is then

$$
g_{\Delta x}(x)=m_{\Delta x} \cdot x+n_{\Delta x}
$$

with

$$
\left(\begin{array}{l}
m_{\Delta x} \\
n_{\Delta x}
\end{array}\right) \cdot\left(\begin{array}{cc}
\int_{x_{t}(\Delta x)}^{x_{s}} x^{2} \cdot d x & \int_{x_{t}(\Delta x)}^{x_{s}} x \cdot d x \\
\int_{x_{t}(\Delta x)}^{x_{s}} x \cdot d x & \int_{x_{t}(\Delta x)}^{x_{s}} d x
\end{array}\right)=\left(\begin{array}{c}
\int_{x_{t}(\Delta x)}^{x_{s}} f(x) \cdot x \cdot d x \\
\int_{x_{t}(\Delta x)}^{x_{s}} f(x) \cdot d x
\end{array}\right) .
$$

With the aid of equivalent lines, the function-oriented parameters can be calculated as

$$
\mathrm{S}_{\mathrm{k}}(\Delta x)=g_{\Delta x}(x=\Delta x)-g_{\Delta x}(x=1),
$$

and

$$
\mathrm{S}_{\mathrm{pk}}(\Delta x)=\underbrace{f(x=\Delta x)}_{=\max (f(x))}-g_{\Delta x}(x=\Delta x)
$$

and

$$
\mathrm{S}_{\mathrm{vk}}(\Delta x)=g_{\Delta x}(x=1)-\underbrace{f(x=1)}_{=\min (f(x))} .
$$

So changing the gradient of the equivalent line impacts the core roughness as well as the reduced peak height and reduced valley height of the topography. While a significant change in the parameter is to be expected for the peaks as a result of the correlation described in eq. 13, the impact on the parameters $S_{k}$ and $S_{v k}$ is only slight, as demonstrated in eq. 12 and eq. 14. The impact of vibratory finishing on the core roughness $S_{k}$ depends particularly on the course of the Abbott curve between the tangent points $x=x_{s}$ and $x=x_{t}$ (Refer to Fig. 6). Greater curvature of the course of the functions means greater changes to $\mathrm{S}_{\mathrm{k}}$. When the Abbott curve is flat, e.g. in the case of rolled surfaces, the parameter changes only slightly. While $S_{k}$ is a factor of the equivalent lines, the parameter to describe the reduced peak height $S_{p k}$ depends primarily on the extent to which the peak was reduced. In addition to the described parameters, the material ratios $\mathrm{S}_{\mathrm{mr} 1}$ and $\mathrm{S}_{\mathrm{mr} 2}$ change as well. These can be estimated on the basis of Fig. 4, with 


$$
\mathrm{S}_{\mathrm{mrl}}(\Delta x)=\left\{x: f(x)=f(\Delta x)-\mathrm{S}_{\mathrm{pk}}(\Delta x)\right\}-\Delta x
$$

and

$$
\mathrm{S}_{\mathrm{mr} 2}(\Delta x)=\left\{x: f(x)=\mathrm{S}_{\mathrm{vk}}(\Delta x)\right\}
$$

and are stated for the sake of completeness.

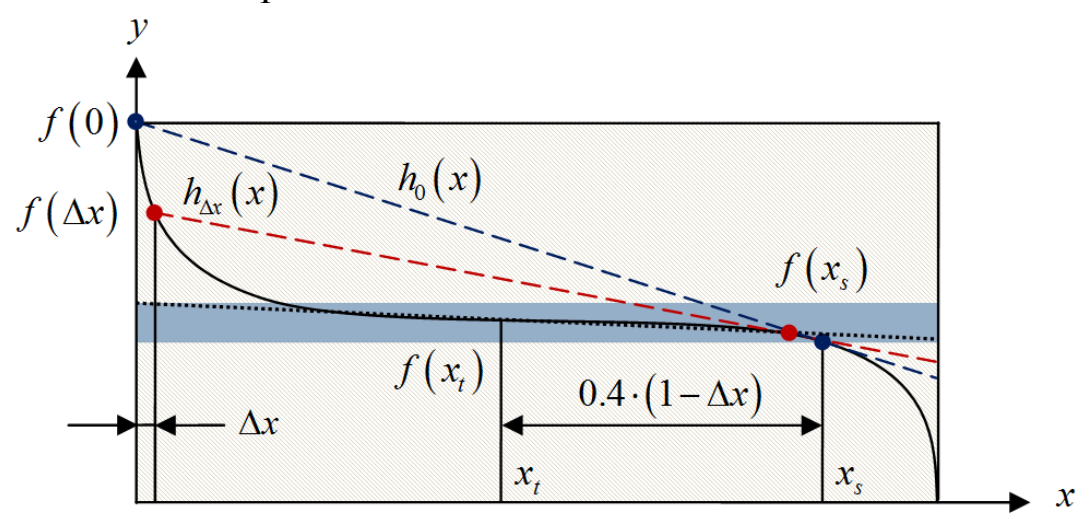

Figure 5. Calculation of the parameters $S_{p k}, S_{k}$ and $S_{v k}$ pursuant to [8] (Refer to Fig. 4) and illustration of the impact of material stripping from the peaks by shifting the material ratio curve by $\Delta x$ along the abscissa. Illustration of the reduced peak height (upper area), the core roughness (middle area) and the reduced valley height (lower area).

\section{Virtual Scattered Light Measurement and Data Analysis}

Although the description of function-oriented parameters demonstrates a causal correlation between the reduction of peaks in a topography and the anticipated change to the function-oriented parameters, there is no direct, functional correlation between the reduction of peaks and the change in gradient distribution of the geometric surface which is ultimately to be measured with the angleresolved scattered light sensor. However, under physical aspects, it can be assumed that the resulting material reduction leads to a decrease in the mean square gradients of the scale-limited surface pursuant to eq. 3 . This is applied to surfaces with considerable roughness, which is the case with the surfaces here (Refer to Fig. 3). To establish that the scattered light sensor is suitable for monitoring of the vibratory finishing process, confocal data recorded at discrete times is used for the evaluation - as described earlier. Because the surface is anisotropic, ten steel samples taken at different times in the course of the process are used to analyze the data. All ten-test samples were prepared either by extrusion, grinding, or sawing machining first and then followed by tumbling process under different time point. Different machining processes (i.e. extruded, grinding, sawing) create different surface texture. We are aiming to see how the tumbling process acts on different surface texture under different tumbling time. The measured surfaces serve as the calculation basis for the scattered light simulation (Refer to virtual measurement setup in Fig. 1). This allows virtual scattering angle distributions to be simulated and then, applying the simulated distributions, $\mathrm{A}_{\mathrm{q}}$ values can be calculated for the discrete processing times (Refer to Table 1 and Fig. 1). An analysis is performed to determine how well the function-oriented parameters correlate to the course of $\mathrm{A}_{\mathrm{q}}$ and $\mathrm{S}_{\mathrm{dq}}$ pursuant to eq. 3 . To examine the correlation between two values $\tilde{x}_{i}$ and $\tilde{y}_{i}$, the coefficient of correlation $\operatorname{corr}_{\tilde{x}, \tilde{y}}$ is calculated. The result is

$$
\operatorname{corr}_{\tilde{x}, \tilde{y}}=\frac{\sum_{i}\left(\tilde{x}_{i}-\overline{\tilde{x}}\right) \cdot\left(\tilde{y}_{i}-\overline{\tilde{y}}\right)}{\sqrt{\sum_{i}\left(\tilde{x}_{i}-\overline{\tilde{x}}\right)^{2}} \cdot \sqrt{\sum_{i}\left(\tilde{y}_{i}-\overline{\tilde{y}}\right)^{2}}} \text { with }-1 \leq \operatorname{corr}_{\tilde{x}, \tilde{y}} \leq+1 \text {. }
$$


To calculate the correlation between $\mathrm{A}_{\mathrm{q}}$ and the course of the value of the reduced peak height $\mathrm{S}_{\mathrm{pk}}$, $\tilde{x}_{i}=\mathrm{A}_{\mathrm{q}, \mathrm{i}}$ and $\tilde{y}_{i}=\mathrm{S}_{\mathrm{pk}, \mathrm{i}}$ may e.g. apply. The index $i$ describes the discrete time step in the vibratory finishing process. Table 1 shows the virtually measured $A_{q}$ values for ten cubic steel samples (sample $A$ to $J$ ) and the discrete processing steps. A decrease in the $A_{q}$ value for the examined samples is apparent, which indicates a decrease in the angle distribution due to an increase in the flat sections. Fig. 7 clearly shows this as well as the course of the trend line.

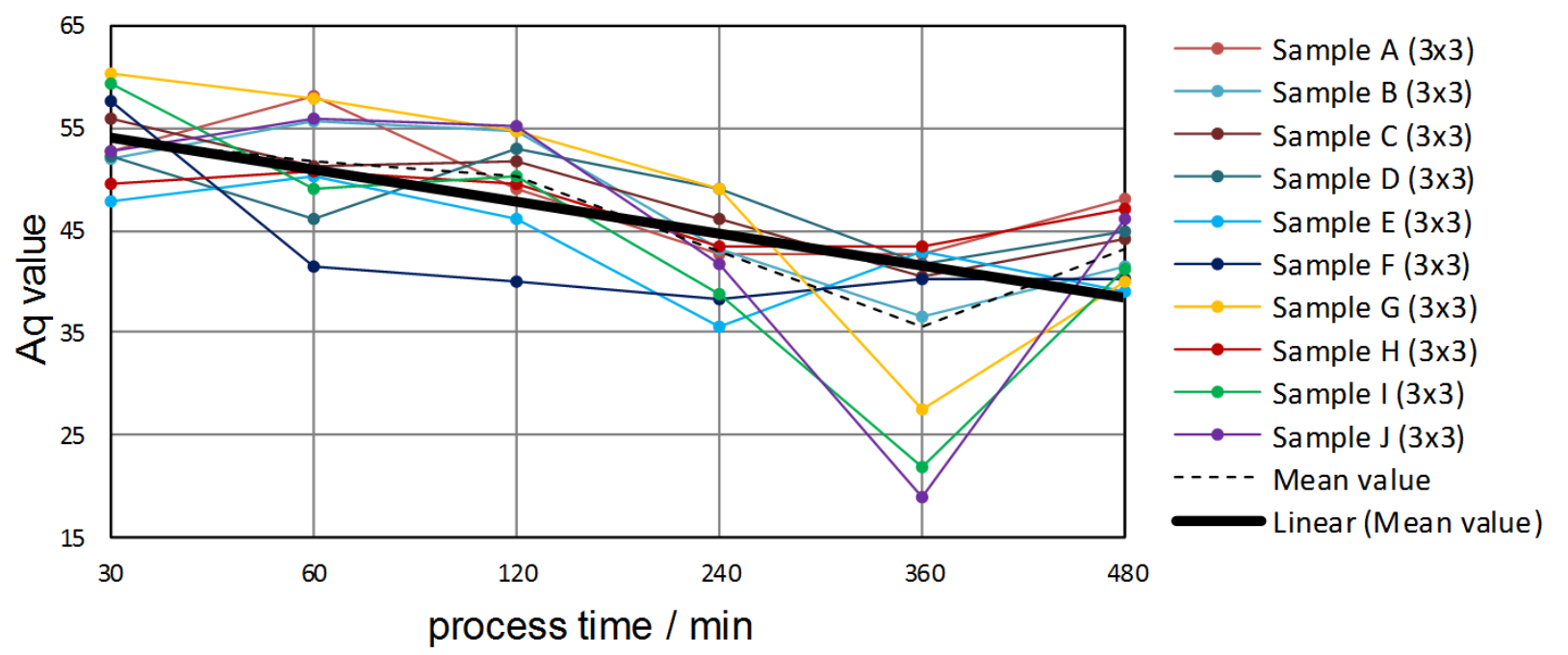

Figure 6. Course of the $A_{q}$ values (measured virtually with ray tracing) during vibratory finishing of ground steel samples, shown as compared to the processing time for samples A to $\mathrm{J}$, based on topography data measured with a confocal microscope and $3 \times 3$ median filtering.

Table 2 provides an overview of the correlation of the course of function-oriented parameters pursuant to eq. 15 that can be calculated on the basis of the material ratio curve. S-filtering of the topography in the sense of [11] was not applied. The results in Table 2 show mostly good correlation for the function-oriented parameters examined. Using the data stated here, the mean coefficients of correlation are calculated to be $66.3 \%\left(\mathrm{~S}_{\mathrm{pk}}\right), 73.4 \%\left(\mathrm{~S}_{\mathrm{k}}\right)$ and $67.9 \%\left(\mathrm{~S}_{\mathrm{vk}}\right)$. Individual variances (Refer to parameter for $\mathrm{S}_{\mathrm{vk}}$, sample $\mathrm{F}$ ) can be attributed to faulty data. Particularly the core roughness $\mathrm{S}_{\mathrm{k}}$ correlates very well to the variance of the scattering angle distribution that can be measured and evaluated directly with the angle-resolved scattered light sensor.

Table 1. Course over time (based on virtual measurements) of $A_{q}$ of ground surfaces (sample 2) in relation to the processing duration of the vibratory finishing process, taking into consideration $3 \times 3$ median filtering of the topography data measured with the confocal microscope.

\begin{tabular}{|c|r|r|r|r|r|r|}
\hline & \multicolumn{7}{|c|}{ Calculated $\mathbf{A}_{\mathbf{q}}$ values for discrete process time steps } \\
\cline { 2 - 7 } & $\mathbf{3 0}$ min & $\mathbf{6 0}$ min & $\mathbf{1 2 0}$ min & $\mathbf{2 4 0}$ min & $\mathbf{3 6 0}$ min & $\mathbf{4 8 0}$ min \\
\hline A & 52.66 & 58.20 & 49.04 & 42.74 & 42.72 & 48.08 \\
\hline B & 51.92 & 55.67 & 54.65 & 43.26 & 36.64 & 41.50 \\
\hline C & 55.82 & 51.19 & 51.79 & 46.04 & 40.56 & 44.06 \\
\hline D & 52.15 & 46.16 & 53.03 & 49.17 & 41.66 & 44.82 \\
\hline E & 47.84 & 50.25 & 46.02 & 35.45 & 42.81 & 38.92 \\
\hline F & 57.65 & 41.38 & 40.02 & 38.38 & 40.26 & 40.28 \\
\hline G & 60.37 & 57.98 & 54.76 & 49.09 & 27.47 & 39.97 \\
\hline H & 49.63 & 50.80 & 49.48 & 43.48 & 43.30 & 46.98 \\
\hline I & 59.43 & 49.00 & 50.17 & 38.84 & 21.83 & 41.31 \\
\hline J & 52.63 & 55.96 & 55.12 & 41.71 & 18.92 & 46.00 \\
\hline
\end{tabular}


Table 2. List of calculated, function-oriented parameters of vibratory-finished surfaces of different samples (sample A to J) at various times during processing. Calculation of coefficient of correlation based on the surfaces actually measured with the confocal microscope and the $A_{q}$ values, measured virtually on the same surfaces, listed in Table 1.

\begin{tabular}{|c|c|c|c|c|c|c|c|c|c|}
\hline \multirow{2}{*}{ Sample } & \multirow{2}{*}{ Parameter } & \multicolumn{6}{|c|}{ Process time steps } & \multirow{2}{*}{\multicolumn{2}{|c|}{$\begin{array}{l}\text { Correlation } \\
\operatorname{corr}_{\tilde{x}, \tilde{y}}\end{array}$}} \\
\hline & & $30 \mathrm{~min}$ & $60 \mathrm{~min}$ & $120 \mathrm{~min}$ & $240 \mathrm{~min}$ & $360 \mathrm{~min}$ & $480 \mathrm{~min}$ & & \\
\hline \multirow{3}{*}{$\mathbf{A}$} & $\mathrm{S}_{\mathrm{pk}}$ & $3.55 \mu \mathrm{m}$ & $2.03 \mu \mathrm{m}$ & $0.74 \mu \mathrm{m}$ & $0.74 \mu \mathrm{m}$ & $0.79 \mu \mathrm{m}$ & $0.57 \mu \mathrm{m}$ & 0.64 & $\checkmark$ \\
\hline & $\mathrm{S}_{\mathrm{k}}$ & $5.97 \mu \mathrm{m}$ & $5.68 \mu \mathrm{m}$ & $4.26 \mu \mathrm{m}$ & $2.49 \mu \mathrm{m}$ & $1.98 \mu \mathrm{m}$ & $1.78 \mu \mathrm{m}$ & 0.84 & $\checkmark$ \\
\hline & $\mathrm{S}_{\mathrm{vk}}$ & $3.55 \mu \mathrm{m}$ & $3.28 \mu \mathrm{m}$ & $3.97 \mu \mathrm{m}$ & $2.59 \mu \mathrm{m}$ & $2.03 \mu \mathrm{m}$ & $2.49 \mu \mathrm{m}$ & 0.63 & $\checkmark$ \\
\hline \multirow{3}{*}{ B } & $\mathrm{S}_{\mathrm{pk}}$ & $4.77 \mu \mathrm{m}$ & $3.94 \mu \mathrm{m}$ & $1.18 \mu \mathrm{m}$ & $0.52 \mu \mathrm{m}$ & $0.76 \mu \mathrm{m}$ & $0.70 \mu \mathrm{m}$ & 0.68 & $\checkmark$ \\
\hline & $\mathrm{S}_{\mathrm{k}}$ & $5.70 \mu \mathrm{m}$ & $4.67 \mu \mathrm{m}$ & $2.90 \mu \mathrm{m}$ & $1.51 \mu \mathrm{m}$ & $1.72 \mu \mathrm{m}$ & $1.85 \mu \mathrm{m}$ & 0.76 & $\checkmark$ \\
\hline & $\mathrm{S}_{\mathrm{vk}}$ & $4.95 \mu \mathrm{m}$ & $5.65 \mu \mathrm{m}$ & $2.69 \mu \mathrm{m}$ & $1.50 \mu \mathrm{m}$ & $1.36 \mu \mathrm{m}$ & $1.36 \mu \mathrm{m}$ & 0.82 & $\checkmark$ \\
\hline \multirow{3}{*}{ C } & $\mathrm{S}_{\mathrm{pk}}$ & $3.75 \mu \mathrm{m}$ & $3.59 \mu \mathrm{m}$ & $1.48 \mu \mathrm{m}$ & $0.79 \mu \mathrm{m}$ & $0.82 \mu \mathrm{m}$ & $0.68 \mu \mathrm{m}$ & 0.82 & $\checkmark$ \\
\hline & $\mathrm{S}_{\mathrm{k}}$ & $4.79 \mu \mathrm{m}$ & $5.56 \mu \mathrm{m}$ & $3.25 \mu \mathrm{m}$ & $2.18 \mu \mathrm{m}$ & $1.79 \mu \mathrm{m}$ & $1.77 \mu \mathrm{m}$ & 0.83 & $\checkmark$ \\
\hline & $\mathrm{S}_{\mathrm{vk}}$ & $2.57 \mu \mathrm{m}$ & $2.50 \mu \mathrm{m}$ & $2.47 \mu \mathrm{m}$ & $1.48 \mu \mathrm{m}$ & $1.10 \mu \mathrm{m}$ & $1.49 \mu \mathrm{m}$ & 0.96 & $\checkmark$ \\
\hline \multirow{3}{*}{ D } & $\mathrm{S}_{\mathrm{pk}}$ & $2.37 \mu \mathrm{m}$ & $2.72 \mu \mathrm{m}$ & $1.32 \mu \mathrm{m}$ & $0.68 \mu \mathrm{m}$ & $0.74 \mu \mathrm{m}$ & $0.50 \mu \mathrm{m}$ & 0.35 & 23 \\
\hline & $\mathrm{S}_{\mathrm{k}}$ & $4.20 \mu \mathrm{m}$ & $4.28 \mu \mathrm{m}$ & $3.02 \mu \mathrm{m}$ & $1.90 \mu \mathrm{m}$ & $1.67 \mu \mathrm{m}$ & $1.58 \mu \mathrm{m}$ & 0.51 & 23 \\
\hline & $\mathrm{S}_{\mathrm{vk}}$ & $2.91 \mu \mathrm{m}$ & $2.81 \mu \mathrm{m}$ & $2.19 \mu \mathrm{m}$ & $1.70 \mu \mathrm{m}$ & $1.14 \mu \mathrm{m}$ & $1.04 \mu \mathrm{m}$ & 0.64 & $V$ \\
\hline \multirow{3}{*}{$\mathbf{E}$} & $\mathrm{S}_{\mathrm{pk}}$ & $3.41 \mu \mathrm{m}$ & $2.84 \mu \mathrm{m}$ & $3.47 \mu \mathrm{m}$ & $1.66 \mu \mathrm{m}$ & $1.75 \mu \mathrm{m}$ & $1.89 \mu \mathrm{m}$ & 0.80 & $\checkmark$ \\
\hline & $\mathrm{S}_{\mathrm{k}}$ & $5.79 \mu \mathrm{m}$ & $6.25 \mu \mathrm{m}$ & $3.96 \mu \mathrm{m}$ & $3.39 \mu \mathrm{m}$ & $2.72 \mu \mathrm{m}$ & $2.10 \mu \mathrm{m}$ & 0.80 & $V$ \\
\hline & $\mathrm{S}_{\mathrm{vk}}$ & $7.48 \mu \mathrm{m}$ & $7.43 \mu \mathrm{m}$ & $6.36 \mu \mathrm{m}$ & $6.11 \mu \mathrm{m}$ & $6.86 \mu \mathrm{m}$ & $5.63 \mu \mathrm{m}$ & 0.82 & $V$ \\
\hline \multirow{3}{*}{$\mathbf{F}$} & $\mathrm{S}_{\mathrm{pk}}$ & $2.25 \mu \mathrm{m}$ & $2.22 \mu \mathrm{m}$ & $1.02 \mu \mathrm{m}$ & $0.78 \mu \mathrm{m}$ & $0.69 \mu \mathrm{m}$ & $0.65 \mu \mathrm{m}$ & 0.69 & $\checkmark$ \\
\hline & $\mathrm{S}_{\mathrm{k}}$ & $5.09 \mu \mathrm{m}$ & $4.97 \mu \mathrm{m}$ & $3.78 \mu \mathrm{m}$ & $2.90 \mu \mathrm{m}$ & $2.33 \mu \mathrm{m}$ & $2.09 \mu \mathrm{m}$ & 0.63 & $V$ \\
\hline & $\mathrm{S}_{\mathrm{vk}}$ & $2.10 \mu \mathrm{m}$ & $2.05 \mu \mathrm{m}$ & $2.01 \mu \mathrm{m}$ & $2.13 \mu \mathrm{m}$ & $1.53 \mu \mathrm{m}$ & $2.55 \mu \mathrm{m}$ & 0.05 & $x$ \\
\hline \multirow{3}{*}{$\mathbf{G}$} & $\mathrm{S}_{\mathrm{pk}}$ & $3.31 \mu \mathrm{m}$ & $2.73 \mu \mathrm{m}$ & $1.91 \mu \mathrm{m}$ & $0.80 \mu \mathrm{m}$ & $1.43 \mu \mathrm{m}$ & $0.78 \mu \mathrm{m}$ & 0.67 & $\checkmark$ \\
\hline & $\mathrm{S}_{\mathrm{k}}$ & $7.44 \mu \mathrm{m}$ & $4.45 \mu \mathrm{m}$ & $3.83 \mu \mathrm{m}$ & $2.05 \mu \mathrm{m}$ & $2.00 \mu \mathrm{m}$ & $2.00 \mu \mathrm{m}$ & 0.75 & $\checkmark$ \\
\hline & $\mathrm{S}_{\mathrm{vk}}$ & $4.88 \mu \mathrm{m}$ & $3.18 \mu \mathrm{m}$ & $3.74 \mu \mathrm{m}$ & $0.95 \mu \mathrm{m}$ & $2.40 \mu \mathrm{m}$ & $1.15 \mu \mathrm{m}$ & 0.58 & 23 \\
\hline \multirow{3}{*}{$\mathbf{H}$} & $\mathrm{S}_{\mathrm{pk}}$ & $3.18 \mu \mathrm{m}$ & $1.83 \mu \mathrm{m}$ & $1.00 \mu \mathrm{m}$ & $0.73 \mu \mathrm{m}$ & $0.74 \mu \mathrm{m}$ & $0.61 \mu \mathrm{m}$ & 0.63 & $\checkmark$ \\
\hline & $\mathrm{S}_{\mathrm{k}}$ & $5.16 \mu \mathrm{m}$ & $4.21 \mu \mathrm{m}$ & $3.46 \mu \mathrm{m}$ & 2.48 & $2.03 \mu \mathrm{m}$ & $1.30 \mu \mathrm{m}$ & 0.71 & $V$ \\
\hline & $\mathrm{S}_{\mathrm{vk}}$ & $3.43 \mu \mathrm{m}$ & $3.02 \mu \mathrm{m}$ & $2.32 \mu \mathrm{m}$ & $1.73 \mu \mathrm{m}$ & $0.76 \mu \mathrm{m}$ & $1.14 \mu \mathrm{m}$ & 0.81 & $\checkmark$ \\
\hline \multirow{3}{*}{ I } & $\mathrm{S}_{\mathrm{pk}}$ & $2.11 \mu \mathrm{m}$ & $2.49 \mu \mathrm{m}$ & $1.09 \mu \mathrm{m}$ & $0.64 \mu \mathrm{m}$ & $0.76 \mu \mathrm{m}$ & $0.51 \mu \mathrm{m}$ & 0.65 & $\checkmark$ \\
\hline & $\mathrm{S}_{\mathrm{k}}$ & $4.01 \mu \mathrm{m}$ & $3.35 \mu \mathrm{m}$ & $2.42 \mu \mathrm{m}$ & $1.76 \mu \mathrm{m}$ & $1.49 \mu \mathrm{m}$ & $1.44 \mu \mathrm{m}$ & 0.82 & $\checkmark$ \\
\hline & $\mathrm{S}_{\mathrm{vk}}$ & $4.10 \mu \mathrm{m}$ & $4.00 \mu \mathrm{m}$ & $2.76 \mu \mathrm{m}$ & $1.45 \mu \mathrm{m}$ & $1.37 \mu \mathrm{m}$ & $0.82 \mu \mathrm{m}$ & 0.75 & $V$ \\
\hline \multirow{3}{*}{$\mathbf{J}$} & $\mathrm{S}_{\mathrm{pk}}$ & $2.98 \mu \mathrm{m}$ & $2.42 \mu \mathrm{m}$ & $1.64 \mu \mathrm{m}$ & $0.84 \mu \mathrm{m}$ & $0.60 \mu \mathrm{m}$ & $0.83 \mu \mathrm{m}$ & 0.70 & $\checkmark$ \\
\hline & $\mathrm{S}_{\mathrm{k}}$ & $4.53 \mu \mathrm{m}$ & $4.49 \mu \mathrm{m}$ & $3.23 \mu \mathrm{m}$ & $2.05 \mu \mathrm{m}$ & $1.71 \mu \mathrm{m}$ & $1.56 \mu \mathrm{m}$ & 0.69 & $\checkmark$ \\
\hline & $\mathrm{S}_{\mathrm{vk}}$ & $3.58 \mu \mathrm{m}$ & $3.42 \mu \mathrm{m}$ & $2.77 \mu \mathrm{m}$ & $2.24 \mu \mathrm{m}$ & $1.71 \mu \mathrm{m}$ & $1.71 \mu \mathrm{m}$ & 0.73 & $V$ \\
\hline
\end{tabular}

$$
\operatorname{corr}_{\tilde{x}, \tilde{y}}>0.60 \quad ; 0.60 \leq \operatorname{corr}_{\tilde{x}, \tilde{y}} \leq 0.30 \Omega ; 0.30>\operatorname{corr}_{\tilde{x}, \tilde{y}}
$$




\section{Summary}

The results of virtual, optical measurements made with the OS500 model of the angle-resolved scattered light sensor manufactured by Optosurf $\mathrm{GmbH}$ in Ettlingen, Germany show that, when the vibratory finishing process is monitored at random points, there is a good correlation between the function-based parameters and the variance of the scattering angle distribution. Because the sensor is highly sensitive to changes in the distribution of the surface angles, it can potentially be used to monitor grinding processes, making it a quick and inexpensive alternative to expensive and timeconsuming confocal or interferometric surface measurement. With only a few exceptions attributable primarily to the topographies examined here as well as measurement errors, the coefficients of correlation between $\mathrm{A}_{\mathrm{q}}$ and the function-oriented parameters are within a range of values that justifies further analysis and actual examinations. So the next step is to perform actual measurements with the OS500 scattered light sensor and to examine the extent to which the virtual model and the real sensor provide comparable results. Since the behavior of the sensor model has already been evaluated in earlier tests, only minimal deviations are to be expected.

Even though the examinations have revealed very good correlations between the parameters, the question of the extent to which the variance of the scattering angle distribution can provide reliable information on function-oriented parameters remains. Thus comprehensive testing and recommendations on the basis of empirical experiences are still needed.

\section{Acknowledgments}

We gratefully acknowledge the manufacturers of the angle-resolved scattered light sensor Dr. Rainer Brodmann and Boris Brodmann as well as Optosurf $\mathrm{GmbH}$ for the pleasant long-term cooperation. We are thankful to Advanced Materials Characterization and Testing Lab (AMCaT) facilities to conduct experimental study. This research was funded by the German research foundation (DFG) within the IRTG 2057 "Physical Modeling for Virtual Manufacturing Systems and Processes".

\section{References}

[1] Seewig, Jörg; Damm, Tobias; Frasch, Janick; Kauven, David ; Rau, Sebastian ; Schnebele, Johannes: Reconstruction of Shape using Gradient Measuring Optical Systems. In: Osten, Wolfgang; Kujawinska, Malgorzata (Hrsg.): Fringe 2009. Berlin, Heidelberg : Springer Berlin Heidelberg, 2009, S. 1-7

[2] Seewig, J.; Beichert, G.; Brodmann, R.; Bodschwinna, H.; Wendel, M.: Extraction of shape and roughness using scattering light. In: SPIE Europe Optical Metrology: SPIE, 2009 (SPIE Proceedings), $73890 \mathrm{~N}$

[3] Linke, Barbara; Das, Jayanti: Aesthetics and Gloss of Ground Surfaces: A Review on Measurement and Generation. In: Journal of Manufacturing Science and Engineering 138 (2016), Nr. 6, S. 64501

[4] Azouigui, S.; Silvestri, Z.; Zerrouki, C.; Bouhtiyya, S.; Plimmer, M. D.; Spaltmann, D.; Kovalev, A. ; Woydt, M.; Pinot, P.: Angle resolved scattering as a tribological investigation tool for surface characterization. In: Wear 326-327 (2015), S. 58-67

[5] Nadal, Maria E. ; Early, Edward A. ; Thompson, Ambler: Specular gloss. Gaithersburg, MD: U.S. Dept. of Commerce, Technology Administration, National Institute of Standards and Technology, Physics Laboratory, Optical Technology Division, 2006 (NIST special publication 250-70)

[6] Oberflächenbeschaffenheit: Geometrische Produktspezifikation; winkelaufgelöste Streulichtmesstechnik; Definition, Kenngrößen und Anwendung. Juli 2010. Berlin : VDA Verband der Automobilindustrie, 2010 (VDA-Empfehlung 2009) 
[7] Norm DIN EN ISO 4287. 07.2010. Geometrische Produktspezifikation (GPS) Oberflächenbeschaffenheit: Tastschnittverfahren - Benennungen, Definitionen und Kenngrößen der Oberflächenbeschaffenheit (ISO 4287:1997 + Cor 1:1998 + Cor 2:2005 + Amd 1:2009); Deutsche Fassung EN ISO 4287:1998 + AC:2008 + A1:2009

[8] Norm DIN EN ISO 25178-2. 09.2012. Geometrische Produktspezifikation (GPS) Oberflächenbeschaffenheit: Flächenhaft - Teil 2: Begriffe und Oberflächen-Kenngrößen (ISO 25178-2:2012); Deutsche Fassung EN ISO 25178-2:2012

[9] Das, Jayanti; Linke, Barbara: Evaluation and systematic selection of significant multi-scale surface roughness parameters (SRPs) as process monitoring index. In: Journal of Materials Processing Technology (2017)

[10] Torner, Francois M.; Stelzer, Gerhard ; Anslinger, Lukas ; Seewig, Jörg: Description and evaluation of a simplified model to simulate the optical behavior of an angle-resolved scattered light sensor. In: Journal of Computing and Information Science in Engineering (2016)

[11] Norm DIN EN ISO 25178-3. 11.2012. Geometrische Produktspezifikation (GPS) Oberflächenbeschaffenheit: Flächenhaft - Teil 3: Spezifikationsoperatoren (ISO 251783:2012); Deutsche Fassung EN ISO 25178-3:2012 